\title{
Can inactivators of plasminogen activator inhibitor alleviate the burden of obesity and diabetes? (Review)
}

\author{
JERZY JANKUN $^{1-3}$, ABDULRAHMAN AL-SENAIDY ${ }^{3}$ and EWA SKRZYPCZAK-JANKUN ${ }^{1}$ \\ ${ }^{1}$ Department of Urology, Urology Research Center, The University of Toledo, Health Science Campus, Toledo, \\ OH 43614, USA; ${ }^{2}$ Department of Clinical Nutrition, Medical University of Gdańsk, 80-211 Gdańsk, Poland; \\ ${ }^{3}$ Protein Research Chair, Department of Biochemistry, College of Sciences, King Saud University, Riyadh, Saudi Arabia
}

Received August 2, 2011; Accepted September 23, 2011

DOI: $10.3892 /$ ijmm.2011.810

\begin{abstract}
Obesity and diabetes once considered 'rich man's diseases' are one of the biggest public health challenges of the 21 st century. Obesity being a gateway to diabetes is a global problem. The supporting statistics are alarming since diabetes is reaching pandemic proportion all over the world. Eighty percent of all patients with diabetes live in developing countries. In this review we describe the role of plasminogen activator inhibitor type one (PAI-1) in the pathology of obesity and diabetes and its potential to be a target in therapy. PAI-1 is the fast acting and specific inhibitor of tissue plasminogen activator (tPA) and urokinase (uPA), the activators of plasminogen and consequently of fibrinolysis. In obesity and diabetes it has been linked to the increased incidence of thrombosis. However, PAI-1 is also involved in the regulation of other proteins engaged in hemostasis. These molecules include transforming growth factor $\beta$ (TGF- $\beta$ ), tumor necrosis factor $\alpha$ (TNF- $\alpha$ ), angiotensin II and interleukin 6 (IL-6), all of which up-regulate PAI-1 in various cell types or can be up-regulated by PAI-1. Thus, PAI-1 plays a critical role in the insulin resistance syndrome, which leads to type 2 diabetes mellitus, and is associated with its side effects such as an increased risk of diabetic nephropathy, atherosclerotic cardiovascular disease and others. Thus inactivating of PAI-1 or increasing its clearance can alleviate the burden of obesity and diabetes.
\end{abstract}

\section{Contents}

1. Introduction

2. Plasminogen activation system

3. PAI-1 in obesity

4. Nutrition, PAI-1 and obesity

5. Risk of diabetes and life style

Correspondence to: Dr Jerzy Jankun, Department of Urology, Urology Research Center, The University of Toledo, Health Science Campus, MS\#1091, 3000 Arlington Ave., Toledo, OH 43614, USA

E-mail: jerzy.jankun@utoledo.edu

Key words: plasminogen activator inhibitor, obesity, diabetes
6. Diabetes and PAI-1

7. Diabetic nephropathy and PAI-1

8. Diabetic vascular disease and PAI-1

9. Inactivators of PAI-1

10. Conclusion

\section{Introduction}

According to the International Diabetes Foundation, diabetes and obesity are the biggest public health challenges of the 21st century. Diabetes once considered a 'rich man's disease' is now a global problem. The supporting statistics are alarming since diabetes is reaching pandemic proportions all over the world. Eighty percent of all patients with diabetes live in developing countries. The highest prevalence of this disease is in the Micronesian island of Nauru, where $31 \%$ of its population has diabetes. The other countries with the highest rates of diabetes are: Bahrain, Egypt, Kuwait, Oman, Saudi Arabia and the United Arab Emirates reaching 27\% of the entire population in some of these countries. In comparison, the diabetes rate is over $10 \%$ of the adults in the USA, Switzerland and Austria (1-4). It is estimated by epidemiologists that during the first thirty years of the 21st century diabetes cases will increase up to 2.5 times in Asia, India, Latin America, the Middle East and Sub-Saharan Africa, with less increase in the economically advanced countries that experienced a rise in diabetes in the 20th century (4). It is estimated that the pandemic of diabetes is caused by the growing prevalence of obesity. However that can depend on the geographical location and it can be slightly less common in men that in women (4).

In this review we concentrate on the role of plasminogen activator inhibitor type one (PAI-1) and the plasminogen activation system (PAS) in the pathology of diabetes and obesity. PAI-1 plays a critical role in the insulin resistance syndrome, which leads to type 2 diabetes mellitus, and is associated with its side effects such as an increased risk of diabetic nephropathy, atherosclerotic cardiovascular disease and others (5).

\section{Plasminogen activation system}

Proteolysis is defined as a degradation of proteins by the proteolytic enzymes. Proteolysis plays a pivotal role in the 
physiological and pathological functions of an organism. It is tightly controlled at the level of expression, activation and inhibition. The PAS is involved in many of the biological processes and depending on disease its overexpression or underexpression can sometimes lead to surprising outcomes (6-9).

The PAS includes: i) Plasminogen, a pro-enzyme activated by cleavage by urokinase (uPA) or tissue plasminogen activator (tPA) that in its active form is called plasmin. Plasmin digests proteins of connective tissue and basement membranes and is able to activate other latent proteolytic enzymes such as pro-collagenase and others. Plasmin is responsible for proteolysis in tissue remodeling, tumor invasion, development of distant metastasis, angiogenesis and fibrinolysis (10). ii) Activators - UPA and tPA. These enzymes are weak proteases that activate plasminogen by proteolytic cleavage; uPA is responsible for activation of pericellular proteolysis during cell migration, wound healing, and tissue remodeling while tPA mainly mediates intravascular thrombolysis (11-13). iii) The binding site of $\mathrm{UPA}$, the $\mathrm{UPA}$ receptor (UPAR). This is a glycoprotein that binds uPA to the cell surface while uPA retains its ability to activate plasminogen (14-16). Urokinase can activate plasminogen to plasmin in the extracellular space as well as while it is receptor-bound. This is similar to the observations during the inactivation by PAI-1, however when the uPA/PAI-1/uPAR complex is formed it is internalized by endocytosis, UPA and PAI-1 are degraded in lysosomes but uPAR is recycled to the surface of cells (17-19). iv) Inhibitors of plasminogen activators. Four proteins have been identified as inhibitors of uPA or tPA, including PAI-1, PAI-2, PAI-3 and a protein called nexin. Most relevant seems to be PAI-1, which exists in three different forms, the active, the non-active/latent and the cleaved form $(8,20)$. PAI-1 is not a stable molecule and converts itself into the latent form $\left(\mathrm{t}_{1 / 2}=1-2 \mathrm{~h}\right)$. During conversion the reactive loop (P10-P4') of PAI-1 is inserted into the central $\beta$-sheet of the protein molecule and the P1-P1' site is not accessible for reaction with tPA or uPA.

Numerous mutations have been observed/introduced into the PAI-1 gene. Some increase the $t_{1 / 2}$ of PAI- 1 while others inactivate it or slow down its secretion into the plasma. It has been found that the $4 \mathrm{G} / 5 \mathrm{G}$ polymorphism at position 675 of the PAI-1 gene promoter increases concentration or PAI-1 activity in the plasma of humans without changing its $t_{1 / 2}$ $(8,21,22)$. The other mutations reduce the concentration or the activity of PAI-1 in plasma. It has been found or postulated that Ala15Thr or Val17Ile SNP is related to the lower secretory dynamics of PAI-1 secretion and the subsequent extended bleeding episodes $(8,23,24)$. The complete PAI-1 deficiency caused by a frame-shift mutation in exon 4 of the PAI-1 gene has been reported for a child with abnormal bleeding and in some members of its extend family $(25,26)$.

Recombinant PAI-1 with mutation in amino acids 369 (P1) and 370 (P1') can have altered affinity to its substrates or be inactive. For example, the Arg369Ala substitution in active site of PAI-1 results in nonactive PAI-1 $(7,8,27)$. Several mutants with extended half-life have been produced in the past $\left(t_{1 / 2}, 6-170 \mathrm{~h}\right)(8,17,20,28-30)$. Historically, the first mutant with extended $t_{1 / 2}$ was reported by Tucker et al (31) $(6 \mathrm{~h})$ while one of the longest ones was produced by Berkenpas et al (20) (up to $170 \mathrm{~h}$ ). The most recently deposited structure PDB ID: 3q02 contains only one mutation Trp198Phe and has stability superior over those listed above $\left(\mathrm{t}_{1 / 2}, 400 \mathrm{~h}\right)$. We have developed 7 other mutants with $t_{1 / 2}$ from 4 to $>700 \mathrm{~h}$ by replacing amino acids with cysteines to form one, two or three disulfide bridges (Cys31-Cys97, Cys192-Cys347, Cys197-Cys355). Most stable is the mutant Cys197-Cys355 called VLHL PAI-1 $(28,32,33)$.

PAI-1 possesses other functions that are not related to proteolysis. It was reported that cancer cells treated in vitro with PAI-1 induced detachment of cancer cells from the vessel surface $(8,18,34)$. It was postulated that disruption of PAI-1 vitronectin and integrin complexes causes cell detachment $(18,34)$. Our own study of this effect showed that treatment of cancer cells with active and highly stable VLHL PAI-1 down-regulates nucleophosmin, while active and latent forms of PAI-1 down-regulated fortilin (34). These two proteins are implicated in cell growth, cell cycle and malignant transformation of cells $(35,36)$. Collectively the data suggest that PAI-1, in addition to its well-known proteolytic properties, plays an important role in cell signaling as well $(18,34-36)$. These processes are driven by unknown mechanism(s) and in all probability involve a conserved part of the PAI-1 molecule (34).

\section{PAI-1 in obesity}

Obesity is a major risk factor for type 2 diabetes mellitus that is associated with chronic inflammation resulting in the activation of the innate immune system. This activation results in release of pro-inflammatory cytokines, such as tumor necrosis factor $\alpha$ (TNF- $\alpha$ ), interleukin- $1 \beta$ (IL-1 $\beta$ ) and interleukin- 6 (IL-6) (37-39). These trigger the production of C-reactive protein, serum amyloid-A, haptoglobin and PAI-1 (37). Under normal physiological conditions PAI-1 secreted bidirectionally by endothelial cells, acts as the primary regulator of fibrinolysis and as a modulator of extracellular matrix proteolysis (40). However in obesity it was postulated that macrophages are more abundant in adipose tissue of obese people than in the individuals of normal weight and are producing various circulating factors including PAI-1. It seems that nutritional factors regulate PAI-1 expression by macrophages. Increased concentrations of free fatty acids in the blood of non-diabetic, overweight people increase the expression of the PAI-1 gene in adipose tissue and raise the concentrations of circulating PAI-1 in blood. Free fatty acids also increase PAI-1 gene expression in adipose macrophages and consequently PAI-1 protein production (41).

Furthermore, Venugopal et al (42) showed that adipose tissue evolved into a major source of PAI-1 production by gaining capacity during adipocyte differentiation in response to inducers of PAI-1 transcription. Skurk and Hauner (43) reported that the greater the fat cell size and the adipose tissue mass, the greater is the contribution of adipose production to circulating PAI-1. They also showed that visceral adipose tissue has a greater capacity to produce PAI-1 than subcutaneous adipose tissue. It was also suggested that PAI-1 synthesis is up-regulated by insulin, glucocorticoids, angiotensin II, some fatty acids and, most potently, by cytokines such as TNF- $\alpha$ and transforming growth factor $\beta$ (TGF- $\beta$ ). PAI-1 overexpression is reversible as it has been noted that comprehensive lifestyle modification and weight loss is effective in lowering PAI-1 plasma levels (43). 
Increased PAI-1 levels have been reported to be the result of obesity by Ma et al (44) who investigated the interrelationships of PAI-1 and obesity in a high-fat/high-carbohydrate diet-induced obesity in wild-type (WT) and PAI-1 deficient mice $\left(\mathrm{PAI}-1^{-/}\right)$. Unexpectedly they found that obesity and insulin resistance development in WT mice on a high-fat/ high-carbohydrate diet were completely prevented in mice lacking PAI-1 (44). Treatment of WT mice on a high-fat/ high-carbohydrate diet with an angiotensin type 1 receptor antagonist to down-regulate PAI-1, inhibited PAI-1 production and reduced obesity induced by diet.

Hoffstedt et al (45) examined whether the PAI-1 gene may cause obesity. They investigated the frequency of a $-6754 \mathrm{G} / 5 \mathrm{G}$ promoter polymorphism in the PAI-1 gene in 188 lean, 70 overweight and 247 obese, but otherwise healthy, Scandinavian people. A deletion/insertion polymorphism within the PAI-1 locus $(4 \mathrm{G} / 5 \mathrm{G})$ affected the expression of this gene. The deletion of $4 \mathrm{G}$ was associated with significantly higher concentrations of PAI-1 than the $4 \mathrm{G} / 5 \mathrm{G}$ insertion. Concentrations of PAI-1 in homozygous $4 \mathrm{G}$ individuals are $\sim 25 \%$ higher than that observed in 5G homozygotes. Homozygosity for 4G was more common among obese people, whereas homozygosity for $5 \mathrm{G}$ was more frequent among lean people. It was concluded that the $-6754 \mathrm{G} / 5 \mathrm{G}$ polymorphism in the PAI-1 gene is strongly linked to obesity in the $4 \mathrm{G}$ allele in its homozygous form.

A higher concentration or activity of PAI-1 increases the risk of venous thromboembolism (VTE). Indeed an analysis at the National Hospital Discharge Survey database showed compelling evidence that obesity is in fact a risk factor for VTE and its recurrence (46).

\section{Nutrition, PAI-1 and obesity}

It was reported that in visceral and subcutaneous adipose tissue PAI-1 mRNA expression is positively correlated with body mass index (BMI). It has also been found that PAI-1 activity/ antigen in plasma are positively and moderately associated with BMI. Moreover weight reduction substantially reduces plasma PAI-1 in obese people $(47,48)$. It has been shown that inhibitors of PAI-1 reduce dietary fat-induced obesity in C57BL/6 mice. Specifically, the authors demonstrated in vivo a dose-dependent effect of PAI-1 inhibition on the reduction of body weight, adipocyte volume, and circulating active PAI-1 in plasma $(47,49)$. Loktionov et al $(50)$ found that tea caused a significant decrease of PAI-1 activity, but only in the subjects with an E2/E3 genotype (mean placebo $7.21 \mathrm{U} / \mathrm{ml}$ vs. mean for tea users $5.88 \mathrm{U} / \mathrm{ml}, \mathrm{P}=0.007$ ) ApoE has six common isoforms: E2/E2, E2/E3, E2/E4, E3/E3, E3/E4 and E4/E4. We have discovered that some theaflavins of black tea inhibit PAI-1 which may provide some explanation for the lower PAI-1 activity in tea lovers $(27,51)$.

There is no clear explanation how inhibitions of PAI-1 can reduce body weight. However, Crandall et al (49) have suggested three possibilities. First, PAI-1 may affect fat tissue growth by changing receptor-dependent transport of lipids into the lipocytes. Alternatively, PAI-1 inhibition may block angiogenesis that will weaken vascularization and consequently growth of the adipose tissue. Finally, inactivation of PAI-1 may stimulate migration of preadipocytes that would prevent their full differentiation into mature fat cells.

\section{Risk of diabetes and life style}

In a large population of people screened, protective features related to type 2 diabetes have been identified which include: moderate alcohol consumption, caffeine, brown rice instead of white rice consumption, healthy eating and exercise habits. Contributory features have been identified as well and these include a high calorie diet, low physical inactivity, aging, sleep deprivation, maternal malnutrition, obesity, chronic physiological stress (52-59). It is not clear if either alcohol or caffeine is indeed responsible for the protective feature or if there is a genetic setup that makes individuals be alcohol or coffee lowers and at the same time protects them form diabetes. Very recently, Cornelis et al (60) reported the a genome-wide association study of habitual caffeine intake on large number $(>47,000)$ individuals within the United States. They found two loci: 7p21 $\left(\mathrm{P}=2.4 \times 10^{-19}\right)$, near AHR, and 15q24 $\left(\mathrm{P}=5.2 \times 10^{-14}\right)$, between CYP1A1 and CYP1A2 associated with high daily caffeine intake. Both the AHR and CYP1A2 genes are plausible candidates as CYP1A2 metabolizes caffeine and AHR regulates CYP1A2. Lane (61) further elaborated this phenomenon. He found that moderate coffee intake increases glucose level, while heavy drinkers that consume 5-7 cups a day can reduce risk of development of type 2 diabetes to $50 \%$. Also he cited a study with a large number of participants $(450,000)$ where daily consumption of coffee was associated with $7 \%$ reduction of type 2 diabetes for each cup drank regardless of glucose increase in moderate coffee drinkers. The exact mechanism remains unclear. He also reported that consumption of sugar-sweetened soft drinks twice a day such as iced tea, fruit drinks, energy drinks increases the risk of type 2 diabetes by $26 \%$ (61).

\section{Diabetes and PAI-1}

PAI-1 levels are elevated in type 2 diabetes, and this elevation correlates with complications of diabetes, although the link between insulin and the up-regulation of PAI-1 is unclear (62). Complicating factor is the ambiguous definition of up-regulation that is described differently by different authors which were using different methods of measuring it (8). Nevertheless Festa et al (63) studied the relation between the incidence of diabetes to the dynamic changes of PAI-1 and fibrinogen. Their study lasted over 5 years and diabetes developed in 140 of 843 individuals. In this study based on a demographically and smoking-adjusted model, the increase of PAI-1 level was related to the incidence of diabetes while correlation with the change in fibrinogen was not significant. Progression of PAI-1 levels over time was associated with rising glucose levels and the development of type 2 diabetes.

Also, Ho and Jap (62) demonstrated that overexpression of Forkhead-related transcription factor FoxO3a enhanced the ability of insulin to activate the PAI-1 promoter. Using small interfering RNA to specifically deplete the Fox transcription factors examined, they demonstrated that reduction of FoxO3a inhibits insulin-increased PAI-1 expression $(62,64)$.

Elevated levels of very low density lipoproteins (VLDL) and triglycerides are biochemical markers of diabetes and other diseases. It was reported that VLDL from diabetic patients increased the generation of PAI-1 from cultured 


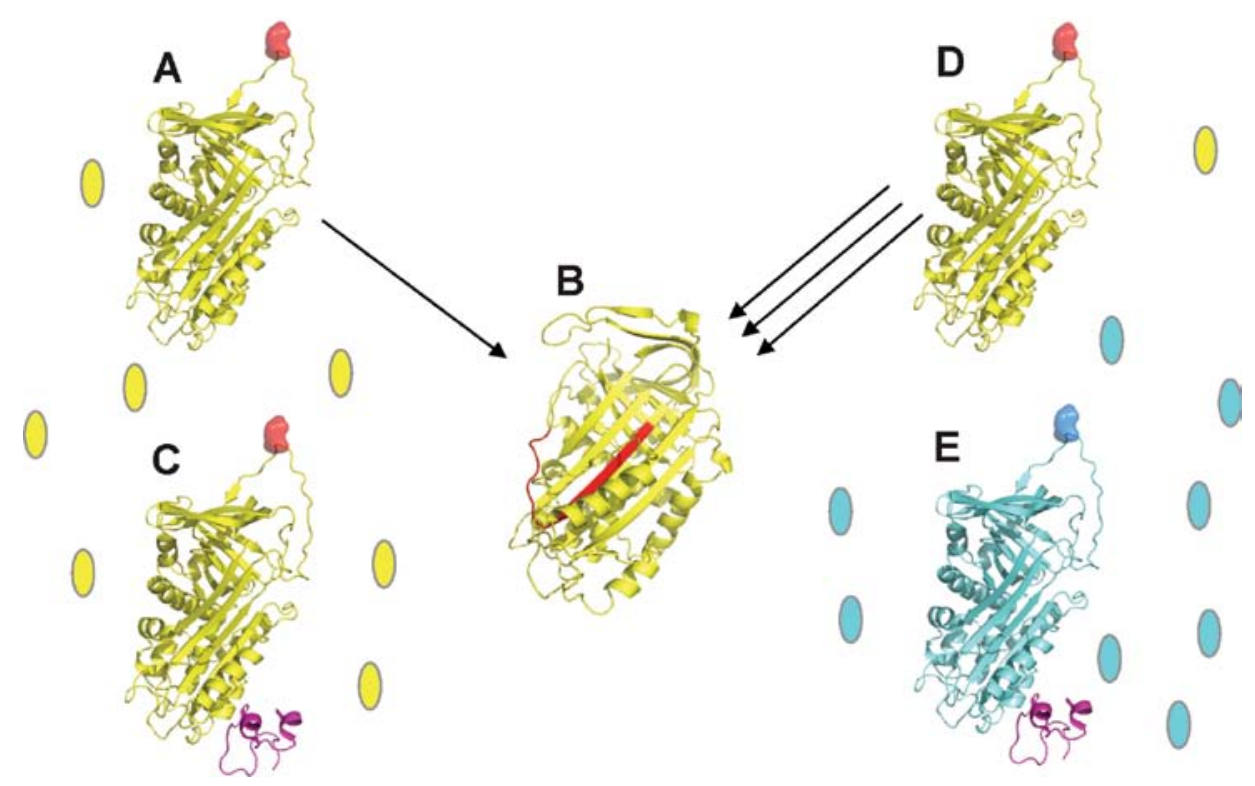

Figure 1. WT PAI-1 (A) quickly converts into the latent form (B) otherwise it is bound to vitronectin (C) which extends its half-life. While the inactive PAI-1R (E) double mutant (Thr356Arg, Ala358Arg) is structurally identical to the active form of PAI-1 when present in excess amount it predominantly binds vitronectin. Thus most of WT PAI-1 (D) would convert into the latent form. Color scheme: yellow WT PAI-1, magenta somatomedin B (SMB) domain of vitronectin, blue PAI-1R, red surface of P1 Arg 369 on reactive loop, red ribbon reactive loop inserted between the A3 and A5 strands in the latent form of PAI-1.

vascular endothelial cells. The authors postulated that heat shock factor-1 (HSF1) is responsible for the transcriptional regulation of PAI-1 in cultured vascular EC or fibroblasts (65).

An elevated plasma level of PAI-1 mediates diabetic vascular complications and suggests diabetic nephropathy to be the major implication of PAI-1 high levels $(66,67)$. The PAI-1 $4 \mathrm{G} / 5 \mathrm{G}$ polymorphism is a cause of high plasma PAI-1 levels in $4 \mathrm{G} / 4 \mathrm{G}$ allele carriers suggesting that the PAI-1 $4 \mathrm{G} / 5 \mathrm{G}$ polymorphism is a genetic risk factor for diabetes. Meigs et al (67) tested this hypothesis among 2169 participants. They concluded that elevated PAI-1 levels may be associated with an increased risk for diabetes and endothelial dysfunction.

The best evidence for a causative role of PAI-1 in diabetes has been provided by Nagi et al (68). They investigated Pima Indians with a very high rate of obesity, insulin-resistance and hyperinsulinemia, which have high rates of diabetes but a low risk of ischemic heart disease and other diabetes complications. In contrast to other ethnic groups, PAI-1 activity is similar between non-diabetic and diabetic Pima Indians (68). Also in a different ethnic group (62) PAI-1 activity was not affected by the increase of glucose, cholesterol, and plasma insulin. They showed that PAI activity in Chinese diabetics was not affected by the common pathological changes found in other populations with diabetes. It was suggested that this is one of the reasons why fibrinolytic activity is not impaired in Chinese diabetics (62). Collectively this suggest that expression of PAI-1 and the complications of diabetes may vary among different population groups and may depend on dietary habits (for example habitually high tea consumption).

\section{Diabetic nephropathy and PAI-1}

It has been suggested that PAI-1 mediates diabetic nephropathy which is characterized by excessive accumulation of extracellular matrix (ECM) in the kidney. Normal human kidney does not express PAI-1, however, PAI-1 is overexpressed in pathological conditions associated with renal fibrosis, including diabetic nephropathy. Tissue plasminogen, urokinase and PAI-1 in kidneys play important roles in ECM remodeling in the kidney. High glucose and the resulting up-regulation of TGF- $\beta 1$ mediate PAI- 1 overexpression in renal cells. Park et al (69) examined the effect of PAI-1 antisense oligodeoxynucleotide on fibronectin up-regulation and plasmin/MMP suppression in primary mesangial cells cultured with high glucose or TGF- $\beta 1$, which are the major mediators of diabetic renal ECM accumulation. They found that high glucose and TGF- $\beta 1$ significantly increased PAI- 1 and fibronectin protein expression and also decreased plasmin and MMP-2 activity.

Studies by Lee et al (70) using PAI-1 ${ }^{-/}$mice suggest that PAI-1 induces ECM deposition in diabetic kidney through increased ECM synthesis by TGF- $\beta 1$ up-regulation and through reduced ECM degradation by suppression of plasmin and MMP-2 activity. Decreased ECM degradation and increased ECM synthesis plays a critical function in ECM remodeling that promotes tissue fibrosis in mouse.

It has been shown that PAI- 1 can regulate TGF- $\beta$ expression by binding to uPAR and activating the extracellular-regulated signal kinase (ERK)/MAPK pathway. Thus, PAI-1 may contribute to diabetic nephropathy by regulating TGF- $\beta$ and renal ECM production. Since TGF- $\beta 1$ is well known to stimulate the PAI-1 promoter, it has been suggested that TGF- $\beta 1$ and PAI-1 together constitute a positive feedback loop in the development of renal fibrosis in diabetes $(71,72)$. Consequently, it has been proposed that PAI-1 may be a therapeutic target in diabetic nephropathy (71). Lassila et al (73) reported that disruption of the PAI-1 gene protects mice against diabetic nephropathy. PAI- $1^{-/}$mice escape obesity and insulin resistance. Different studies assessed the effects of PAI-1 deficiency on the renal disease in experimental diabetes in the mouse. 
Diabetes was induced by injection of streptozotocin in 6-weekold PAI-1-deficient mice, and transgenic mice overproducing PAI-1 in comparison with WT mice. PAI-1 message was higher in kidneys from genetically normal mice with diabetes and in non-diabetic PAI-1 transgenic mice. Diabetes-associated glomerular injury, albuminuria and renal $\alpha$-smooth muscle actin production, were ameliorated in diabetic PAI-deficient mice in comparison with diabetic transgenic and WT mice. It was concluded that endogenous PAI-1 deficiency protects mice from glomerular injury (73).

A PAI-1 inhibitor may thus prove therapeutic not only as an anti-thrombotic agent but also in other clinical conditions, such as obesity, diabetes and possibly fibrotic diseases $(71,74)$. Unfortunately, only a few PAI-1 inhibitors have been identified so far and their clinical potential is yet to be evaluated (74).

A very interesting approach to PAI-1-induced diabetic nephropathy was proposed by Huang et al (75). Short term administration of a PAI-1 mutant that has no proteinase-inhibitory activity, but otherwise remains in an active conformation (PAI-1R) slows down the progression of glomerulosclerosis in the $\mathrm{db} / \mathrm{db}$ mouse [the $\mathrm{db} / \mathrm{db}$ mouse is a model of obesity and diabetes homozygous for a point mutation in the leptin receptor gene (76)], in which mesangial matrix accumulation is evident by 140 days of age. They observed that PAI-1R increases glomerular plasmin generation, reverses PAI-1 inhibition of matrix degradation, and consequently reduces symptoms of disease in experimental glomerulonephritis. Used as a control, non-treated $\mathrm{db} / \mathrm{db}$ mice developed progressive albuminuria and mesangial matrix expansion evident between days 140 and 154. PAI-1 in the plasma binds to vitronectin that extends its half life. The authors suggest that PAI-1R interferes with WT-PAI-1/vitronectin binding by saturating vitronectin with PAI-1R. Consequently WT-PAI-1 not complexed with vitronectin converts quickly to the latent form and the anti-protease activity of PAI-1 is diminished (Fig. 1). They conclude that the ability of PAI-1 to inhibit ECM degradation is dependent both on maintaining an active conformation and on its antiproteinase activity which PAI-1R does not have $(75,77)$.

\section{Diabetic vascular disease and PAI-1}

PAI-1 is a major anti-fibrinolytic glycoprotein thought to promote vascular diseases in general and in diabetes in particular $(78,79)$. A hypercoagulable state due to overactive PAI-1 as indicated by decreased fibrinolysis and increased coagulability is one of the factors responsible for the development of cardiovascular complications of diabetes mellitus (78). One of the health risks that overwhelm the person with diabetes is cardiovascular disease and especially coronary heart disease, cerebrovascular and peripheral vascular disease which represent the heaviest burden (80). Keen et al (80) reported that the survey in diabetic individuals revealed the elevated levels of PAI-1 among others (von Willebrand factor, fibrinogen, factor VII) as being responsible for cardiovascular disease in diabetic patients.

Others have reported that diabetes mellitus is accompanied by volatility of the blood's fluid-coagulating equilibrium, which contributes to the initiation and development of the micro- and macro-vascular complications (81). Elevated PAI-1 activity most likely plays a critical role in the pathogenesis of macrovascular diseases in patients with diabetes (82). Disturbances in the hemostatic system promote the development of vascular damage and the occlusion events in coronary heart disease. Juhan-Vague et al (83) have suggested that increased concentration of factor VII, von Willebrand factor, fibrinogen, PAI-1 and tPA are risk factors for coronary heart disease. After reviewing recent experiments from animal models of thrombosis, it becomes obvious that a pathogenic decreased fibrinolytic activity or increased PAI-1 levels could play a critical role in the development of vascular disease in patients with type 2 diabetes.

Lopes et al (84) analyzed genetic contributions of PAI-1 mutations to the diabetes and to its complications for over 1,000 unrelated individuals of a French Caucasian cohort, selected for diabetes and obesity. They were looking for an association between PAI-1 polymorphisms and phenotypes related to diabetes. The authors found five SNP variants of which two promoter polymorphisms were associated with higher fasting glucose concentrations $(\mathrm{P}=0.006$ and $\mathrm{P}=0.0004$, for -765 $4 \mathrm{G} / 5 \mathrm{G}$ and $-844 \mathrm{~A}>\mathrm{G}$, respectively) and insulin $(\mathrm{P}=0.05$ and $\mathrm{P}=0.008$, for $-7654 \mathrm{G} / 5 \mathrm{G}$ and $-844 \mathrm{~A}>\mathrm{G}$, respectively) (84). They suggest that PAI-1 polymorphisms probably induce a more severe insulin-resistant metabolic profile in diabetes, and further increase the risk for coronary heart disease in diabetic patients (84).

Increased PAI-1 leads to decreased tPA activities and impairs fibrinolysis, which is critical in cardiovascular disease. Umpaichitra et al (85) studied hemostatic factors in 12 type 2 diabetics and 17 non-diabetic obese adolescents. They analyzed plasma PAI-1, tPA, glucose, serum C-peptide, insulin and others. Fasting PAI-1 activities were significantly greater in diabetics than in control subjects $(23.4 \pm 2.6$ vs. $12.9 \pm 2.0 \mathrm{U} / \mathrm{ml}$; $\mathrm{P}<0.004)$, while fasting tPA activities were significantly lower $(0.8 \pm 0.3$ vs. $6.5 \pm 2.7 \mathrm{U} / \mathrm{ml} ; \mathrm{P}<0.001)$. They concluded that elevated PAI-1 and lower tPA activities suppress fibrinolysis in adolescents with type 2 diabetes adding the risk factor for cardiovascular disease. Trost et al (86) reported that patients with insulin resistance and a manifested cluster of risk factors for cardiovascular disease may lower the risk of cardiovascular complications by enforcing weight loss and decreasing concentrations of PAI-1.

\section{Inactivators of PAI-1}

PAI-1 can be inhibited by antibody or small molecule inhibitors. The monoclonal antibodies can inactivate PAI-1 by different mechanisms: a) by preventing formation of the Michaelis complex between the substrate and PAI-1; b) by accelerating the transition from the active to the latent form; or c) by inducing turnover of the PAI-1 protease complex as a substrate (87-89). Several small molecule inhibitors have been found to inhibit PAI-1 via varying mechanisms. For example AR-H029953XX $(90)$ and PAI-039 $(91,92)$ inhibitors bind to the hydrophobic cleft region around $\alpha$-helices $\mathrm{D}$ and $\mathrm{E}$ and $\beta$-strand 1A (Fig. 2A). This part of PAI-1 molecule is known to act as a flexible joint while $\beta$-sheet $A$ opens and the reactive center loop of PAI- 1 is inserted as $\beta$-strand 4A. The authors hypothesize that inhibition of PAI-1 happens not by prevention of the interaction between PAI-1 and the substrate, but by inhibiting the formation of a stable covalent complex, 


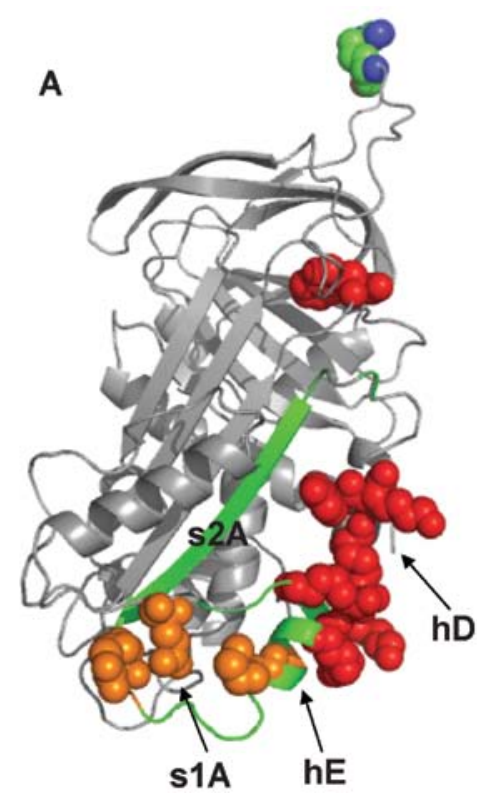

B

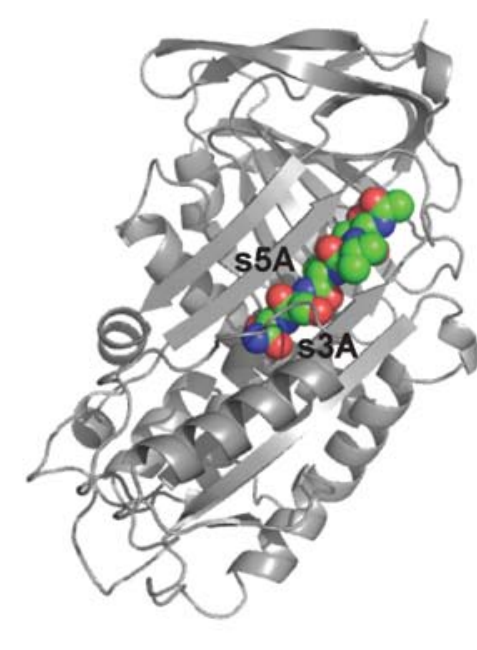

Figure 2. (A) Ribbon model of active PAI-1 (3R4L), Arg369 of the active site is shown as spheres colored by atom type (carbon, green; nitrogen, blue; oxygen, red); amino acids 110-145 postulated by Rupin et al (96) as an inhibitor binding site shown in green; residues critical for the primary binding site of vitronectin are shown in orange (Arg126, Met133, Gln146); residues critical for the secondary binding site of vitronectin (Lys92, Arg99, Tyr102, Lys103, Arg138, Arg141, Trp198) are shown in red (103). Helices (hD, hE) and a strand (s1A) are partially obstructed by amino acids shown as spheres. (B) Cleaved PAI-1 (1A7C) with polypeptide shown as spheres colored by atom type (101). PAI-1 inhibitors were docked below this peptide between sA3 and sA5.

that has to be formed to act on uPA or tPA. This site is in the proximity of the vitronectin biding region and when PAI-1 is preincubated with vitronectin some of these organochemicals loose their inhibitory activity $(87,90)$. Moreover, preincubation of PAI-1 with PAI-039 blocks binding of PAI-1 to vitronectin supporting this hypothesis. However, it does not exclude a possibility that PAI-039 binds to different secondary sites (87,90,93-95). A broader binding site has been proposed for the S35225 PAI-1 inhibitor. It was postulated that this inhibitor binds to the PAI-1 fibrin binding area that encompasses amino acid residues 110-145 (96). This includes the vitronectin binding site and since PAI-1 binds to fibrin via vitronectin (97) it is possible that authors mistakenly named the vitronectin binding site as fibrin binding site. A similar binding site was proposed for the XR5118 PAI-1 inactivator (98). A different binding site was postulated by Gardell et al (99). The PAI-749 small molecule inhibitor could block formation of the initial, reversible Michaelis complex between PAI-1 and its target protease; this indicates that binding in the proximity of Arg369 in the reactive center loop (RCL) of PAI-1 (100) or alerting the RCL conformation to disable the insertion of Arg into the specificity pocket of uPA or tPA. Izuhara et al (95) using molecular modeling methods proposed different binding sites for PAI-1 inhibitors. Taking advantage of the known structure of cleaved PAI-1 (101) with polypeptide (1a7c) they docked several small chemicals into the gap between $\mathrm{A} 3$ and A5 $\beta$-sheet A (Fig. 2B). They found several organochemicals that bind to this gap. One of these chemicals was PAI-039 supporting the assumption of two binding sites of this molecule into PAI-1. These novel chemicals were later found to inhibit PAI-1. It must be underscored that modeling was done for inactive, cleaved PAI-1, but it is assumed that these inhibitors open strands sA 3 and sA5 and bind between them in the active form of PAI-1. However, the PAI-1 activity neutralizing mechanism in this case remains illusive and difficult to comprehend. These examples do not include all known inhibitors but rather were intended to illustrate the complexity of PAI-1 inactivation.

\section{Conclusion}

Increased circulating PAI- 1 concentrations and activity are a hallmark of obesity and type 2 diabetes. PAI-1 is mostly synthesized in adipose tissue, and circulating PAI-1 levels and activity correlate with body mass index, markers for insulin resistance and complications of diabetes in human studies. TGF- $\beta 1$ stimulates the expression of PAI- 1 in obesity which is further stimulated by glucose, insulin and VLDL. Also, PAI-1 can stimulate TGF- $\beta 1$ expression creating a positive feedback loop. Furthermore, some studies suggest that the converse is to be true, specifically, that PAI-1 contributes to the development of obesity and diabetes and its complications (102-104). The therapeutic potential of PAI-1 inhibitors in obesity and diabetes can be utilized by blocking PAI- 1 activity or by increasing its clearance from the circulation by inactive PAI-1. However, future development of PAI-1-based therapeutics requires clarification that remedial activity is indeed related to mediation of proteolytic activity or that it possibly interferes with other functions of PAI-1. Critical for the further advancement of knowledge will be the determination of binding site(s) of these chemicals to PAI-1 and understanding their mechanism of action.

\section{Acknowledgements}

This study was supported in part by a grant from the Stranahan Endowment Fund for Oncological Research. We thank Dr R. Hart (President, PharmaIP LLC, Greenwich, CT, USA) for helpful remarks, discussions and a long term support. 


\section{References}

1. Al-Baghli NA, Al-Ghamdi AJ, Al-Turki KA, Al Elq AH, El-Zubaier AG and Bahnassy A: Prevalence of diabetes mellitus and impaired fasting glucose levels in the Eastern Province of Saudi Arabia: results of a screening campaign. Singapore Med J 51: 923-930, 2010

2. Alqurashi KA, Aljabri KS and Bokhari SA: Prevalence of diabetes mellitus in a Saudi community. Ann Saudi Med 31: 19-23, 2011.

3. Diabetes - a global threat (Editorial). Lancet 373: 1735, 2009.

4. Ginter E and Simko V: Diabetes type 2 pandemic in 21 st century. Bratisl Lek Listy 111: 134-137, 2010.

5. Steinberger J and Daniels SR: Obesity, insulin resistance, diabetes, and cardiovascular risk in children: an American Heart Association scientific statement from the Atherosclerosis, Hypertension, and Obesity in the Young Committee (Council on Cardiovascular Disease in the Young) and the Diabetes Committee (Council on Nutrition, Physical Activity, and Metabolism). Circulation 107: 1448-1453, 2003.

6. Jankun J, Aleem AM, Selman SH, Basrur V and SkrzypczakJankun E: VLHL plasminogen activator inhibitor spontaneously reactivates from the latent to active form. Int J Mol Med 23: 57-63, 2009.

7. Jankun J, Aleem AM, Struniawski R, Lysiak-Szydlowska W, Selman SH and Skrzypczak-Jankun E: Accelerated thrombus lysis in the blood of plasminogen activator inhibitor deficient mice is inhibited by PAI-1 with a very long half-life. Pharmacol Rep 61: 673-680, 2009.

8. Jankun J and Skrzypczak-Jankun E: Yin and yang of the plasminogen activator inhibitor. Pol Arch Med Wewn 119: 410-417, 2009

9. Swiercz R, Keck RW, Skrzypczak-Jankun E, Selman SH and Jankun J: Recombinant PAI-1 inhibits angiogenesis and reduces size of LNCaP prostate cancer xenografts in SCID mice. Oncol Rep 8: 463-470, 2001.

10. Iishi H, Tatsuta M, Baba M, Yano H, Uehara H and Nakaizumi A: Suppression by amiloride of bombesin-enhanced peritoneal metastasis of intestinal adenocarcinomas induced by azoxymethane. Int J Cancer 63: 716-719, 1995.

11. Kook YH, Adamski J, Zelent A and Ossowski L: The effect of antisense inhibition of urokinase receptor in human squamous cell carcinoma on malignancy. EMBO J 13: 3983-3991, 1994

12. Ossowski L: In vivo invasion of modified chorioallantoic membrane by tumor cells: the role of cell surface-bound urokinase. J Cell Biol 107: 2437-2445, 1988.

13. Ossowski L: Invasion of connective tissue by human carcinoma cell lines: requirement for urokinase, urokinase receptor, and interstitial collagenase. Cancer Res 52: 6754-6760, 1992.

14. Berger DH: Plasmin/plasminogen system in colorectal cancer. World J Surg 26: 767-771, 2002.

15. Kwaan HC: The plasminogen-plasmin system in malignancy Cancer Metastasis Rev 11: 291-311, 1992.

16. Kwaan HC and McMahon B: The role of plasminogen-plasmin system in cancer. Cancer Treat Res 148: 43-66, 2009.

17. Cortese K, Sahores M, Madsen CD, Tacchetti C and Blasi F: Clathrin and LRP-1-independent constitutive endocytosis and recycling of UPAR. PLoS One 3: e3730, 2008.

18. Czekay RP, Aertgeerts K, Curriden SA and Loskutoff DJ: Plasminogen activator inhibitor-1 detaches cells from extracellular matrices by inactivating integrins. J Cell Biol 160: 781-791, 2003.

19. Poliakov A, Tkachuk V, Ovchinnikova T, Potapenko N, Bagryantsev S and Stepanova V: Plasmin-dependent elimination of the growth-factor-like domain in urokinase causes its rapid cellular uptake and degradation. Biochem J 355: 639-645, 2001.

20. Berkenpas MB, Lawrence DA and Ginsburg D: Molecular evolution of plasminogen activator inhibitor-1 functional stability. EMBO J 14: 2969-2977, 1995.

21. Dawson SJ, Wiman B, Hamsten A, Green F, Humphries S and Henney AM: The two allele sequences of a common polymorphism in the promoter of the plasminogen activator inhibitor(PAI-1) gene respond differently to interleukin-1 in HepG2 cells J Biol Chem 268: 10739-10745, 1993.

22. Wiklund PG, Nilsson L, Ardnor SN, et al: Plasminogen activator inhibitor- $14 \mathrm{G} / 5 \mathrm{G}$ polymorphism and risk of stroke: replicated findings in two nested case-control studies based on independent cohorts. Stroke 36: 1661-1665, 2005

23. Jankun J and Skrzypczak-Jankun E: Bleeding diathesis is associated with an A15T heterozygous mutation in exon 2 of the plasminogen activator inhibitor type 1. Exp Ther Med 1: 575-577, 2010
24. Zhang ZY, Wang ZY, Dong NZ, Bai X, Zhang W and Ruan CG: A case of deficiency of plasma plasminogen activator inhibitor-1 related to Ala15Thr mutation in its signal peptide. Blood Coagul Fibrinolysis 16: 79-84, 2005.

25. Fay WP, Parker AC, Condrey LR and Shapiro AD: Human plasminogen activator inhibitor-1 (PAI-1) deficiency: characterization of a large kindred with a null mutation in the PAI-1 gene. Blood 90: 204-208, 1997.

26. Fay WP, Shapiro AD, Shih JL, Schleef RR and Ginsburg D: Brief report: complete deficiency of plasminogen-activator inhibitor type 1 due to a frame-shift mutation. N Engl J Med 327: 1729-1733, 1992.

27. Jankun J, Skotnicka M, Lysiak-Szydlowska W, Al-Senaidy A and Skrzypczak-Jankun E: Diverse inhibition of plasminogen activator inhibitor type 1 by theaflavins of black tea. Int J Mol Med 27: 525-529, 2011.

28. Chorostowska-Wynimko J, Swiercz R, Skrzypczak-Jankun E, Wojtowicz A, Selman SH and Jankun J: A novel form of the plasminogen activator inhibitor created by cysteine mutations extends its half-life: relevance to cancer and angiogenesis. Mol Cancer Ther 2: 19-28, 2003.

29. De Taeye B, Gils A and Declerck PJ: The story of the serpin plasminogen activator inhibitor 1: is there any need for another mutant? Thromb Haemost 92: 898-924, 2004

30. Vleugels N, Leys J, Knockaert I and Declerck PJ: Effect of stabilizing versus destabilizing interactions on plasminogen activator inhibitor-1. J Pharm Belg 55: 57-58, 2000.

31. Tucker HM, Mottonen J, Goldsmith EJ and Gerard RD: Engineering of plasminogen activator inhibitor-1 to reduce the rate of latency transition. Nat Struct Biol 2: 442-445, 1995.

32. Stoop AA, Jespers L, Lasters I, Eldering E and Pannekoek H High-density mutagenesis by combined DNA shuffling and phage display to assign essential amino acid residues in protein-protein interactions: application to study structure-function of plasminogen activation inhibitor 1 (PAI-I). J Mol Biol 301: 1135-1147, 2000.

33. Verstraete M: Newer thrombolytic agents. Ann Acad Med Singapore 28: 424-433, 1999.

34. Jankun J, Aleem AM, Specht Z, et al: PAI-1 induces cell detachment, down-regulates nucleophosmin (B23) and fortilin (TCTP) in LnCAP prostate cancer cells. Int J Mol Med 20: 11-20, 2007.

35. Tuynder M, Fiucci G, Prieur S, et al: Translationally controlled tumor protein is a target of tumor reversion. Proc Natl Acad Sci USA 101: 15364-15369, 2004

36. Tuynder M, Susini L, Prieur S, et al: Biological models and genes of tumor reversion: cellular reprogramming through tpt1/TCTP and SIAH-1. Proc Natl Acad Sci USA 99: 14976-14981, 2002

37. Badawi A, Klip A, Haddad P, et al: Type 2 diabetes mellitus and inflammation: prospects for biomarkers of risk and nutritional intervention. Diabetes Metab Syndr Obes 3: 173-186, 2010.

38. Birgel M, Gottschling-Zeller H, Rohrig K and Hauner H: Role of cytokines in the regulation of plasminogen activator inhibitor-1 expression and secretion in newly differentiated subcutaneous human adipocytes. Arterioscler Thromb Vasc Biol 20: 1682-1687, 2000 .

39. Samad F and Loskutoff DJ: The fat mouse: a powerful genetic model to study elevated plasminogen activator inhibitor 1 in obesity/NIDDM. Thromb Haemost 78: 652-655, 1997.

40. Grant MB, Ellis EA, Caballero S and Mames RN: Plasminogen activator inhibitor-1 overexpression in nonproliferative diabetic retinopathy. Exp Eye Res 63: 233-244, 1996.

41. Kishore P, Li W, Tonelli J, et al: Adipocyte-derived factors potentiate nutrient-induced production of plasminogen activator inhibitor-1 by macrophages. Sci Transl Med 2: 20ra15, 2010.

42. Venugopal J, Hanashiro K and Nagamine Y: Regulation of PAI-1 gene expression during adipogenesis. J Cell Biochem 101: 369-380, 2007

43. Skurk T and Hauner H: Obesity and impaired fibrinolysis: role of adipose production of plasminogen activator inhibitor-1. Int $\mathrm{J}$ Obes Relat Metab Disord 28: 1357-1364, 2004.

44. Ma LJ, Mao SL, Taylor KL, et al: Prevention of obesity and insulin resistance in mice lacking plasminogen activator inhibitor 1. Diabetes 53: 336-346, 2004.

45. Hoffstedt J, Andersson IL, Persson L, Isaksson B and Arner P: The common $-6754 \mathrm{G} / 5 \mathrm{G}$ polymorphism in the plasminogen activator inhibitor -1 gene is strongly associated with obesity. Diabetologia 45: 584-587, 2002.

46. Stein PD and Goldman J: Obesity and thromboembolic disease. Clin Chest Med 30: 489-493, 2009.

47. Correia ML and Haynes WG: A role for plasminogen activator inhibitor-1 in obesity: from pie to PAI? Arterioscler Thromb Vasc Biol 26: 2183-2185, 2006. 
48. Mavri A, Alessi MC, Bastelica D, et al: Subcutaneous abdominal, but not femoral fat expression of plasminogen activator inhibitor-1 (PAI-1) is related to plasma PAI-1 levels and insulin resistance and decreases after weight loss. Diabetologia 44: 2025-2031, 2001.

49. Crandall DL, Quinet EM, El Ayachi S, et al: Modulation of adipose tissue development by pharmacological inhibition of PAI-1. Arterioscler Thromb Vasc Biol 26: 2209-2215, 2006.

50. Loktionov A, Bingham SA, Vorster H, Jerling JC, Runswick SA and Cummings JH: Apolipoprotein E genotype modulates the effect of black tea drinking on blood lipids and blood coagulation factors: a pilot study. Br J Nutr 79: 133-139, 1998.

51. Skrzypczak-Jankun E and Jankun J: Theaflavin digallate inactivates plasminogen activator inhibitor: could tea help in Alzheimer's disease and obesity? Int J Mol Med 26: 45-50, 2010

52. Hu FB, Manson JE, Stampfer MJ, et al: Diet, lifestyle, and the risk of type 2 diabetes mellitus in women. N Engl J Med 345: 790-797, 2001

53. Koppes LL, Dekker JM, Hendriks HF, Bouter LM and Heine RJ Moderate alcohol consumption lowers the risk of type 2 diabetes: a meta-analysis of prospective observational studies. Diabetes Care 28: 719-725, 2005.

54. Koppes LL, Dekker JM, Hendriks HF, Bouter LM and Heine RJ : Meta-analysis of the relationship between alcohol consumption and coronary heart disease and mortality in type 2 diabetic patients. Diabetologia 49: 648-652, 2006.

55. Mallon L, Broman JE and Hetta J: High incidence of diabetes in men with sleep complaints or short sleep duration: a 12-year follow-up study of a middle-aged population. Diabetes Care 28 : 2762-2767, 2005.

56. Robertson R and Powers A (eds): Type 2 Diabetes, Update. The Endocrine Society, Chevy Chase, 2011

57. Sun Q, Spiegelman D, van Dam RM, et al: White rice, brown rice, and risk of type 2 diabetes in US men and women. Arch Intern Med 170: 961-969, 2010.

58. van Dam RM and Hu FB: Coffee consumption and risk of type 2 diabetes: a systematic review. JAMA 294: 97-104, 2005.

59. van Dam RM, Willett WC, Manson JE and Hu FB: Coffee, caffeine, and risk of type 2 diabetes: a prospective cohort study in younger and middle-aged US women. Diabetes Care 29: 398-403, 2006.

60. Cornelis MC, Monda KL, Yu K, et al: Genome-wide metaanalysis identifies regions on 7p21 (AHR) and 15q24 (CYP1A2) as determinants of habitual caffeine consumption. PLoS Genet 7: e1002033, 2011

61. Lane J: Caffeine, glucose metabolism, and type 2 diabetes. J Caffeine Res 1: 23-28, 2011.

62. Ho CH and Jap TS: Relationship of plasminogen activator inhibitor-1 with plasma insulin, glucose, triglyceride and cholesterol in Chinese patients with diabetes. Thromb Res 69: 271-277, 1993.

63. Festa A, Williams K, Tracy RP, Wagenknecht LE and Haffner SM: Progression of plasminogen activator inhibitor-1 and fibrinogen levels in relation to incident type 2 diabetes. Circulation 113 : 1753-1759, 2006.

64. Jag UR, Zavadil J and Stanley FM: Insulin acts through FOXO3a to activate transcription of plasminogen activator inhibitor type 1 . Mol Endocrinol 23: 1587-1602, 2009.

65. Zhao R, Ma X and Shen GX: Transcriptional regulation of plasminogen activator inhibitor-1 in vascular endothelial cells induced by oxidized very low density lipoproteins. Mol Cell Biochem 317: 197-204, 2008.

66. Collins SJ, Alexander SL, Lopez-Guisa JM, et al: Plasminogen activator inhibitor-1 deficiency has renal benefits but some adverse systemic consequences in diabetic mice. Nephron Exp Nephrol 104: e23-e34, 2006.

67. Meigs JB, Dupuis J, Liu C, et al: PAI-1 Gene 4G/5G polymorphism and risk of type 2 diabetes in a population-based sample. Obesity (Silver Spring) 14: 753-758, 2006

68. Nagi DK, Tracy R and Pratley R: Relationship of hepatic and peripheral insulin resistance with plasminogen activator inhibitor-1 in Pima Indians. Metabolism 45: 1243-1247, 1996.

69. Park J, Seo JY and Ha H: Plasminogen activator inhibitor-1 antisense oligodeoxynucleotides abrogate mesangial fibronectin accumulation. Korean J Physiol Pharmacol 14: 385-390, 2010.

70. Lee $\mathrm{HB}$ and $\mathrm{Ha} \mathrm{H}$ : Plasminogen activator inhibitor-1 and diabetic nephropathy. Nephrology (Carlton) 10 (Suppl): S11-S13, 2005.

71. Nicholas SB, Aguiniga E, Ren Y, et al: Plasminogen activator inhibitor-1 deficiency retards diabetic nephropathy. Kidney Int 67: 1297-1307, 2005 .
72. Seo JY, Park J, Yu MR, Kim YS, Ha H and Lee HB: Positive feedback loop between plasminogen activator inhibitor-1 and transforming growth factor-betal during renal fibrosis in diabetes. Am J Nephrol 30: 481-490, 2009.

73. Lassila M, Fukami K, Jandeleit-Dahm K, et al: Plasminogen activator inhibitor-1 production is pathogenetic in experimental murine diabetic renal disease. Diabetologia 50: 1315-1326, 2007.

74. Miyata T and van Ypersele de Strihou C: Translation of basic science into clinical medicine: novel targets for diabetic nephropathy. Nephrol Dial Transplant 24: 1373-1377, 2009.

75. Huang Y, Border WA, Lawrence DA and Noble NA: Mechanisms underlying the antifibrotic properties of noninhibitory PAI-1 (PAI-1R) in experimental nephritis. Am J Physiol Renal Physiol 297: F1045-F1054, 2009.

76. Oh KS, Kim EY, Yoon M and Lee CM: Swim training improves leptin receptor deficiency-induced obesity and lipid disorder by activating uncoupling proteins. Exp Mol Med 39: 385-394, 2007.

77. Huang Y, Border WA, Yu L, Zhang J, Lawrence DA and Noble NA: A PAI-1 mutant, PAI-1R, slows progression of diabetic nephropathy. J Am Soc Nephrol 19: 329-338, 2008.

78. Madan R, Gupt B, Saluja S, Kansra UC, Tripathi BK and Guliani BP: Coagulation profile in diabetes and its association with diabetic microvascular complications. J Assoc Physicians India 58: 481-484, 2010

79. Venugopal B, Sharon R, Abramovitz R, Khasin A and Miskin R: Plasminogen activator inhibitor-1 in cardiovascular cells: rapid induction after injecting mice with kainate or adrenergic agents. Cardiovasc Res 49: 476-483, 2001.

80. Keen $\mathrm{H}$, Clark $\mathrm{C}$ and Laakso M: Reducing the burden of diabetes: managing cardiovascular disease. Diabetes Metab Res Rev 15: 186-196, 1999.

81. Sfredel V, Mota M, Traila A,Danoiu S and Matcas H: Disturbances of the coagulating equilibrium of blood in diabetes mellitus. Rom J Intern Med 37: 251-260, 1999.

82. Nagi DK, Knowler WC, Hanson RL, Ali VM and Yudkin JS: Plasminogen activator inhibitor (PAI-1) and non-insulin-dependent diabetes in Pima Indians, south Asians and Europeans. Populations at varying risk of NIDDM and coronary artery disease. Thromb Haemost 75: 921-927, 1996.

83. Juhan-Vague I, Alessi MC and Vague P: Thrombogenic and fibrinolytic factors and cardiovascular risk in non-insulin-dependent diabetes mellitus. Ann Med 28: 371-380, 1996.

84. Lopes C, Dina C, Durand E and Froguel P: PAI-1 polymorphisms modulate phenotypes associated with the metabolic syndrome in obese and diabetic Caucasian population. Diabetologia 46: 1284-1290, 2003.

85. Umpaichitra V, Hussain MM and Castells S: Plasminogen activator inhibitor-1 and tissue-plasminogen activator in minority adolescents with type 2 diabetes and obesity. Pediatr Res 58: 483-487, 2005.

86. Trost S, Pratley R and Sobel B: Impaired fibrinolysis and risk for cardiovascular disease in the metabolic syndrome and type 2 diabetes. Curr Diab Rep 6: 47-54, 2006.

87. Gorlatova NV, Cale JM, Elokdah H, et al: Mechanism of inactivation of plasminogen activator inhibitor-1 by a small molecule inhibitor. J Biol Chem 282: 9288-9296, 2007.

88. Naessens D, Gils A, Compernolle G and Declerck PJ: Elucidation of a novel epitope of a substrate-inducing monoclonal antibody against the serpin PAI-1. J Thromb Haemost 1: 1028-1033, 2003.

89. Verhamme I, Kvassman JO, Day D, et al: Accelerated conversion of human plasminogen activator inhibitor-1 to its latent form by antibody binding. J Biol Chem 274: 17511-17517, 1999.

90. Egelund R, Einholm AP, Pedersen KE, et al: A regulatory hydrophobic area in the flexible joint region of plasminogen activator inhibitor-1, defined with fluorescent activity-neutralizing ligands. Ligand-induced serpin polymerization. J Biol Chem 276: 13077-13086, 2001.

91. Crandall DL, Hennan JK, Elokdah H, et al: WAY-140312 reduces plasma PAI-1 while maintaining normal platelet aggregation. Biochem Biophys Res Commun 311: 904-908, 2003.

92. Elokdah H, Abou-Gharbia M, Hennan JK, et al: Tiplaxtinin, a novel, orally efficacious inhibitor of plasminogen activator inhibitor-1: design, synthesis, and preclinical characterization. J Med Chem 47: 3491-3494, 2004.

93. Cale JM,Li SH, Warnock M, et al: Characterization of a novel class of polyphenolic inhibitors of plasminogen activator inhibitor-1. J Biol Chem 285: 7892-7902, 2010.

94. Crandall DL, Elokdah H, Di L, Hennan JK, Gorlatova NV and Lawrence DA: Characterization and comparative evaluation of a structurally unique PAI-1 inhibitor exhibiting oral in-vivo efficacy. J Thromb Haemost 2: 1422-1428, 2004. 
95. Izuhara Y, Takahashi S, Nangaku M, et al: Inhibition of plasminogen activator inhibitor-1: its mechanism and effectiveness on coagulation and fibrosis. Arterioscler Thromb Vasc Biol 28: 672-677, 2008

96. Rupin A, Gaertner R, Mennecier P, et al: S35225 is a direct inhibitor of plasminogen activator inhibitor type-1 activity in the blood. Thromb Res 122: 265-270, 2008.

97. Podor TJ, Peterson CB, Lawrence DA, et al: Type 1 plasminogen activator inhibitor binds to fibrin via vitronectin. J Biol Chem 275: 19788-19794, 2000.

98. Friederich PW, Levi M, Biemond BJ, et al: Novel low-molecular-weight inhibitor of PAI-1 (XR5118) promotes endogenous fibrinolysis and reduces postthrombolysis thrombus growth in rabbits. Circulation 96: 916-921, 1997.

99. Gardell SJ, Krueger JA, Antrilli TA, et al: Neutralization of plasminogen activator inhibitor I (PAI-1) by the synthetic antagonist PAI-749 via a dual mechanism of action. Mol Pharmacol 72: 897-906, 2007.
100. Lin Z, Jiang L, Yuan C, et al: Structural basis for recognition of urokinase-type plasminogen activator by plasminogen activator inhibitor-1. J Biol Chem 286: 7027-7032, 2011.

101. Xue Y, Bjorquist $\mathrm{P}$, Inghardt $\mathrm{T}$, et al: Interfering with the inhibitory mechanism of serpins: crystal structure of a complex formed between cleaved plasminogen activator inhibitor type 1 and a reactive-centre loop peptide. Structure 6: 627-636, 1998.

102. Alessi MC, Bastelica D, Morange P, et al: Plasminogen activator inhibitor 1, transforming growth factor-beta1, and BMI are closely associated in human adipose tissue during morbid obesity. Diabetes 49: 1374-1380, 2000.

103. Brown NJ: Therapeutic potential of plasminogen activator inhibitor-1 inhibitors. Ther Adv Cardiovasc Dis 4: 315-324, 2010.

104. Grant PJ: Diabetes mellitus as a prothrombotic condition. J Intern Med 262: 157-172, 2007. 